\title{
Feasibility assessment of longevity swap for the Korean life annuity market
}

\author{
Changsoo Lee $^{a}$, Jimin Hong ${ }^{1, a}$, Seongmin Kim ${ }^{a}$ \\ ${ }^{a}$ Department of Statistics and Actuarial Science, Soongsil University, Korea
}

\begin{abstract}
This study analyzes the premium risk of insurers in Korea, which is expected to experience the fastest population aging in the world. Based on the Lee-Carter model, we generate 10,000 scenarios for the number of future survivors in the group of the 10,000 policyholders of life annuity. According to the result of simulation study, the probability of insurer's loss for both groups of male and female policyholders is very low. This result indicates that the premium risk of insurers is not as great as the insurer's concern. This study also suggests introduction of the longevity swap as an alternative to manage the premium risk for the insurer which sells life annuity products. The longevity swap allows insurers to hedge premium risk and reduce capital burden due to the premium risk inherent in life annuity. This study also shows through examples that the counterparty of swap deal may have excess profit in exchange for taking premium risk.
\end{abstract}

Keywords: life annuity, longevity risk, longevity swap, Lee-Carter model

\section{Introduction}

According to the "State of World Population 2020" published by the United Nations Population Fund (UNFPA) on June 2020, (South) Korea's total fertility rate was 1.1 children per woman , the lowest in the world. The fertility rate is also significantly lower than the world average of 2.4 births per woman; In fact, the total fertility rate was at 0.84 in 2020, recording 0.08 from a year earlier, the lowest ever. Among Korea's total population, the proportion of persons 0 to 14 years old accounted for $12.5 \%$, only half of the world's average $(25.4 \%)$. Only two countries, Japan(12.4\%) and Singapore(12.3\%) have a lower ratio of 0 to 14 years of age than Korea. On the other hand, 15.8\% of the population was aged 65 or older in Korea, far higher than the world average(9.3\%). There may be some differences in outlooks depending on the analyst, but there is no doubt that Korea will experience a more serious aging population than Japan in the near future with a sharp increase in life expectancy. Korea is experiencing an unprecedented rapid aging amongst the world. According to the United Nations (UN), a society can be classified as aging if the proportion of people aged 65 or older is $7 \%$ or higher, an aged society if they are $14 \%$ or more, and a super-aged society if they are more than $20 \%$. According to an analysis by the U.S. Census Bureau (2015), based on this standard, Korea is a rapidly aging population, which is expected to become a super-aged society in 2027, only 27 years after becoming an aging society in 2000 . This is 10 years faster than Japan, which is currently experiencing the highest level of aging.

A report by the UN (2015) shows the rapid aging of Korea's population as well. The report provides trends and forecasts of the median age of the total population of each country. The report

\footnotetext{
${ }^{1}$ Corresponding author: Department of Statistics and Actuarial Science, Soongsil University, 369, Sangdo-ro, Dongjakgu, Seoul 06978, Korea. E-mail: jmhong @ssu.ac.kr
}

Published 30 November 2021 / journal homepage: http://csam.or.kr

(C) 2021 The Korean Statistical Society, and Korean International Statistical Society. All rights reserved. 
predicts that Korea will become the "oldest population" nation in the world, predicting a median age of 53.9 years in 2050. That is, in 2015, the average age of Korean was about the same as the average of other members of OECD countries, but by 2050, Korea is highly likely to become a country with the highest proportion of older citizens.

The problem of population aging can negatively affect various aspects of society. In particular, if poverty of the elderly worsens along with the progress of an aging population, the aging problem gets worse. This is because an increase in the proportion of the elderly due to the aging population will ultimately lead to a huge burden on national finances if a number of elderly people do not have proper preparation for retirement. This may also lead to a variety of economic and social conflicts.

However, despite the rapid population aging in Korea, preparations for this are very insufficient. In particular, the problem of poor preparation for old age is the most serious. According to the OECD (2017), Korea's elderly poverty rate is $45.7 \%$, the highest among the 35 OECD countries. In order to solve poverty for the elderly, activation of an annuity market can be considered. Currently, the pension replacement rate in Korea is $34.6 \%$, which is only $65 \%$ of the OECD average. Note that the average OECD pension replacement rate is around 52.9\%. However, guaranteeing an income through public annuity is facing a limit due to the deteriorating finance of the National Pension Fund. Thus, vitalizing the private annuity market will be considered as an alternative.

Meanwhile, insurers in Korea are not actively selling annuity. The reason for this passive attitude of insurers includes their lack of expertise in annuity and changes in the regulatory environment. In particular, the introduction of IFRS 17 and the strengthening of the solvency system serve as reasons for reducing the activities of insurers in selling annuity. The above changes in regulation require insurers to expand large-scale capital and an advanced risk management for debt. It is clear that products with long-term maturities such as annuity are not generally preferred by insurers because they increase the difficulties in risk management and capital expansion without taking special measures.

This study aims to find effective alternatives for risk management by focusing on premium risk, which is one of the reasons for such passive attitudes among insurers. In this study, premium risk refers that the insured live longer than expected and consequently, insurance premium is underestimated and the payment of insurance benefit is greater than expected. The Lee-Carter model, a representative future mortality estimation model, is used to evaluate the level of premium risk of Korean insurers; and based on this, we propose the longevity swap contract which has already been commercialized in developed countries as a way to respond to changes in the regulatory environment, such as the introduction of IFRS17 and the strengthening of the solvency system. Note that the contract between Swiss Re and Friends Provident in April 2007 was evaluated as the first longevity swap in an economic sense (Kwon and Jang, 2011).

The studies related to this research are as follows: Lee and Carter (1992) present a mortality estimation prediction model of a simple structure with age and period. Booth et al. (2002) modify the method to adjust the time component (period) to reproduce the age distribution of deaths and address the non-linearity in time component. Renshaw and Haberman (2003) extend the Lee-Cater model with age-specific enhancement. Callot et al. (2016) propose to separate the deterministic and stochastic time series components to improve fitting and forecasting. However, as pointed by Andrew and Blake (2021), these extended models are less popular in practice because the higher order period functions behave complicatedly and thus, is difficult to forecast.

Meanwhile, Cairns-Blake-Dowd models (CBD model) are emerged as alternatives to the LeeCater model. Cairns et al. (2006a) suggest a two-factor model at which the first factor affects mortality rate dynamics in the same way at all ages, while the second factor affects more at higher ages than at lower ages. This CBD model is extended by Cairns et al. (2006b) to general CBD-style models 
which consider an interaction between age, period and cohorts. The Lee-Carter model and CBD models are progressed as the hybrid model by Plat (2009). Plat (2009) use a static age function arising in the Lee-Carter model, multiple parametric age functions in CBD models and a cohort term in age/period/cohort models (APC models). Note that APC mortality models belong to the general class of generalized non-linear models (GNMs). Mitchell et al. (2013) and Haberman and Renshaw (2012, 2013) develop APC models with mortality improvement rates, rather than mortality rates.

In this study, the basic Lee-Carter model is used to estimate the mortality. As pointed out by Blake and Tickle (2008), Lee-Carter model is the dominant method in forecasting of mortality. Several literature apply this model to forecast the mortality. Wilmonth (1996) forecasts the mortality of Japan using Lee-Carter model. Tuljapurkar et al. (2000) examine mortality in the G7 countries (Canada, France, Germany, Italy, Japan, UK and US) applying Lee-Carter model and find that median forecasts of life expectancy are higher than the official forecast which already exist. Hollmann et al. (2000) also apply Lee-Carter model into US census data to forecast the long-term life expectancy. Booth and Tickle (2003) point out that the official mortality projection for Australian is underestimated especially in female and oldest-old populations using Lee-Carter model. Lundstrom and Qvist (2004) investigate the mortality of Sweden based on the Lee-Carter model.

Meanwhile, this research is also relevant to the studies on how to manage the premium risk. The most representative way is to transfer the premium risk to the market. Blake and Burrows (2001) introduce the survivor bond, in which a coupon payment amount is linked to the number of survivors of the reference group. Cowley and Cummins (2005) review the securitization of life insurance and annuity and show that premium risk can be managed by securitization. Dowd et al. (2006) argue that longevity swap is easy to develop and has a flexible structure, making it suitable for insurers to manage and hedge the premium risk. Biffs et al. (2016) show that the credit risk of longevity swap can be mitigated by collateralization on the marking to market using theoretical model. Coughlan $e t$ al. (2007) introduce q-forward, which is a mortality forward rate contract for transferring premium risk. Sung and Shin (2007) introduce derivatives such as longevity bonds and argue for the necessity of related research. Kim (2012b) compares eight stochastic mortality models for measuring longevity risk in Korea. Kwon and Jang (2011) review premium risk management techniques, such as longevity swaps and longevity bonds, as a means of hedging the premium risk of insurers, and review cases of issuing longevity bonds abroad. Michaelson and Mulholland (2014), Cairns and El Boukfaoui (2018) discuss the longevity bull call spread to hedge the premium risk. Hunt and Blake (2015) analyze the design of the Kortis bond, which is a longevity trend bond and developed to hedge the premium risk of Swiss Re. Note that the Kortis bond is linked to the divergence in improvement rates of mortality between two countries. Blake et al. (2019) point out that longevity swap has been the most successful solutions to transfer premium risk and argue the needs for innovation such as reinsurance sidecars.

Our study is meaningful in predicting the future mortality trend in Korea using the Lee-Carter model on the basis of previous studies. Booth and Tickle (2003) state that the two-factor Lee-Carter model applied in this study is successful in accuracy. Thus, based on the Lee-Carter model, we evaluate the level of premium risk of Korean insurers due to the sales of life annuities. We also review the availability of longevity swaps as a means of activating the life annuity market in response to changes in the regulatory environment.

The remainder of this paper is organized as follows. In Section 2, we address the current status of the private annuity market in Korea. In Section 3, we describe the characteristics of data, model and methodology for analyzing premium risk. In Section 4, we evaluate the level of premium risk for insurers in Korea due to the sales of life annuities. In Section 5, we examine the possibility longevity swap transactions in Korea by presenting a simple longevity swap structure. In Section 6, 
Table 1: Annual premium of annuity savings

(Unit : KRW, \%)

\begin{tabular}{ccccccc}
\hline \hline \multicolumn{3}{c}{ Total annual premiums } & & \multicolumn{2}{c}{ Total annual premiums } \\
\cline { 5 - 6 } \cline { 5 - 6 } & \multicolumn{2}{c}{2018} & & \multicolumn{2}{c}{2018} \\
\hline $\begin{array}{c}102,168 \\
\text { (billion) }\end{array}$ & $\begin{array}{c}100,803 \\
\text { (billion) }\end{array}$ & $-3.10 \%$ & & $\begin{array}{c}2,250 \\
\text { (thousand) }\end{array}$ & $\begin{array}{c}2,350 \\
\text { (thousand) }\end{array}$ & $4.40 \%$ \\
\hline \hline
\end{tabular}

Source : FSS(2019)

we conclude.

\section{Life annuity market in Korea}

Annuities are classified into public annuities (national pension) and private annuities (retirement pension, personal annuity) according to the operating entity. Most countries have introduced and operated a public-oriented system for annuities to ensure a proper retirement income for individuals. However, as concerns about the sustainability of public annuities have emerged due to aging and slowing economic growth, many countries are moving toward strengthening the role of private annuities instead of reducing the role of public annuities through national pension reform. In the case of Korea, a multi-layered retirement income guarantee system is provided, but there is a limit to the operation of functions to prepare for retirement. The fact that Korea's elderly poverty rate is very high clearly shows this limitation. Given the current pace of population aging in Korea, relying solely on public annuity cannot be a solution. Therefore, it is essential to strengthen the function of private annuities. In particular, the expansion of the role of personal annuities should be emphasized. Considering the high number of self-employed and irregular workers in Korea, the number of retirement pension recipients is limited.

However, so far, the role of personal annuities in Korea is not sufficient in terms of quantity and quality. According to the results of the analysis for annuity-saving in 2018 by the Financial Supervisory Service (FSS) of Korea (2019), the number of annuity-saving holders at the end of 2018 was 562.8 million, a mere $0.4 \%$ increase from the previous year, and the participation rate was around $30 \%$ compared to the number of wage earners(18.28 million). In addition, at the end of 2018, the accumulated personal annuity reserves amounted to 337.7 trillion won, which is only $28.9 \%$ of the total reserves for public and private annuities. Considering that the annuity market is shifting towards private annuity in advanced countries, these statistics show that the quantitative growth of private annuity as a means of guaranteeing retirement income is insufficient.

Furthermore, through analysis of the current status of premium, guaranteed period and payments for annuity-saving holders, it can be confirmed that the quality of personal annuities as a means of guaranteeing retirement income is also low. Compared to 2017, the total premium for annuity-saving in 2018 decreased by $1.3 \%$, and the premium per contract was 2.35 million won, which is $58.8 \%$ of the tax credit limit(4 million won). In addition, only $32.7 \%$ of the total annuity was in whole life annuity, and the average period for temporary life annuity was only 6.8 years. Lastly, the payment per contract was only 260,000 won per month $(3,800,000$ won per year) in average, so its function as a means of guaranteeing retirement income is limited as well.

In order to overcome aging and insufficient annuity-saving, and to achieve progress in reinforcing the role of personal annuity to guarantee retirement income, there are many problems to be solved. First of all, doubts about whether annuity premiums are appropriate and the long-term solvency of insurers have been factors that lower the possibility of activation in personal annuity. In addition, insurers are reluctant to sell annuity actively because of the decrease in profitability due to long- 
Table 2: Types of annuity savings

\begin{tabular}{ccccc}
\hline \hline & Fixed period & Fixed amount & Whole life & Others \\
\hline 2018 & $65.40 \%$ & $1.70 \%$ & $32.70 \%$ & $0.20 \%$ \\
2017 & $66.00 \%$ & $1.40 \%$ & $32.40 \%$ & $0.20 \%$ \\
\hline \hline
\end{tabular}

Source : FSS(2019)

lasting low interest rates, the increase in insurance debt against premium risks, capital expansion due to the introduction of IFRS 17, and the strengthening of the solvency system.

This study discusses a longevity swap as a way to expand the function of annuity. A longevity swap is a risk management tool that has already been commercialized in advanced countries as a means to efficiently manage the premium risk.

\section{Model, data and methodology}

\subsection{The model for premium risk}

In a broad sense, longevity risk refers to all the risks posed by an increase in people's life expectancy, but in more detail, there are some differences in the definition of longevity risk depending on the purpose and subject of the study. In this study, premium risk included in longevity risk is defined as the burden from financial loss that insurers suffer from changes in mortality rate trends that are beyond expectations. That is, the present value of additional annuity payments is defined as the premium risk as insurers who set an appropriate insurance premium for annuity based on forecasts of future mortality trends experience a decline in the mortality rate beyond this expectation.

In this study, the Lee-Carter model was used to estimate the future mortality rate (or probability of future survival) of insureds (for annuity) in Korea. The Lee-Carter model is a stochastic model for mortality rate proposed by American statisticians Ronald D. Lee and Lawrence Carter in 1992. The Lee-Carter model is a nonlinear time series estimation model that reflects age and period effects, and has been used as a representative stochastic mortality rate model due to its simplicity and ease of estimation. The Lee-Carter model is expressed as follows.

$$
\operatorname{In}\left(m_{x, t}\right)=\alpha_{x}+\beta_{x} k_{t}+\varepsilon_{x, t} .
$$

In (3.1), $m_{x, t}$, which is $D_{x, t} / L_{x, t}$, indicates the central death rate for an individual aged $x$ at time $t$, where is the average number of individuals aged $x$ at time $\mathrm{t}$ and $D_{x, t}$ is the number of deaths aged $x$ at time $t . \alpha_{x}$ is the coefficient which describes the average pattern of death rate in each age, $k_{t}$ is the coefficient which describes the pattern of improvement of death rate at time $t$ and is the sensitivity for $k_{t}$ in each age. In addition, the following constraint is needed to guarantee the uniqueness of coefficients in the Lee-Carter model.

$$
\sum_{x}^{\beta_{x}}=1 \quad \text { and } \quad \sum_{t}^{k_{i}=0}
$$

Lee and Carter (1992) use the method of singular value decomposition (SVD) and Wilmoth (1996) suggests weighted least squares (WLS) and maximum likelihood estimation (MLE) to estimate the Lee-Carter model. In this study, we adopt the SVD approach. According to Kim (2012a), estimating the Lee-Carter model using the population and death date provided by the Statistics Korea, the difference in results is not significantly large between the estimation methods. 
Meanwhile, the prediction of future mortality rate through the Lee-Carter model is possible by the identifying of with ARIMA model and obtaining the forecasts of $k_{t}$. In this study, as in Lee and Carter (1992), the predicted value of $k_{t}$ is calculated by fitting $k_{t}$ into ARIMA $(0,1,0)$. Note that Kim (2012a) identifies the parameters of $\operatorname{ARIMA}(p, d, q)$ model for $k_{t}$ estimated from the mortality rate of Korea and suggests ARIMA $(0,1,0)$ and ARIMA $(0,1,1)$ for man and woman.

\subsection{Data and analysis}

The procedure of the entire analysis is as follows. At the first stage, we set the model for mortality rate of the annuity holders using the Lee-Carter model. The basic data to derive the mortality rate is the (Complete) Life Tables provided by Statistics Korea. However, since the population of Life Tables is the whole individuals of a nation, there may be a difference from this study in which the annuity holders are considered as a population. Therefore, this study includes the step of correcting the difference between the two populations by setting a simple assumption. At the second stage, a scenario for future death (survivor) is created using the results of future mortality for the annuity holders derived in the previous stage. The process of generating these scenarios reflects not only the volatility of the mortality model itself, but also the independence of survival among the annuity holders. At the third stage, the premium risk of the insurers is evaluated by deriving the probability distribution of insurer's profit using the scenarios created in the previous stage. At the last stage, a longevity swap contract structure that can satisfy both insurers and the counterparties is proposed by using the probability distribution of the insurer's profit, and the transaction possibility is evaluated.

As noted above, to fit the mortality model and to estimate the future mortality rate for annuity holders through the Lee-Carter model, male and female mortality data based on 46 Life Tables from 1970 to 2015 provided by Statistics Korea is used. The maximum age of the Life Tables is up to 100 years old and is classified into one-year units. In December 2015, Statistics Korea improved the method of compiling Life Tables and began to provide the mortality data for each age from 1970 to 2000 , extending the upper limit age from 80 to 100 . Prior to the improvement, as the data on the mortality rate with an upper limit of 100 years is provided only for the period after 2000, there was a problem with sufficient data on the mortality of the super-aged( 80 years or older), which should be more importantly addressed in studies of premium risk but could not be obtained. Previous studies have either lowered the upper limit age under 80 years old to secure the sufficient data, or used a limited data period since 2000 even though it was insufficient. Note that Kim (2012b) also confines the data periods to ages 50 to 79 years old in order to compare eight stochastic models for measuring the premium risk of Korea. For this reason, there exists a limitation in that the mortality of the super-aged was insufficiently incorporated into the research on the premium risk of Korea. However, with the improvement, this study can significantly address the lack of data periods, enabling more sophisticated premium risk evaluation.

In addition, to evaluate the premium risk of insurers, it is necessary to calculate the premium applied when selling annuity. In this study, the internal raw data for the reference net premium rates of the $8^{\text {th }}$ experience mortality table from Korea Insurance Development Institute are used as a basis for calculating the annuity premium. The reference net premium rate for individuals is divided into the reference net premium rate I $\left(q_{x}^{\text {RefI }}\right)$ and the reference net premium rate II $\left(q_{x}^{R e f I I}\right)$. The reference net premium II is a rate that reflects the consideration for taking risks from the policyholders. That is, it is a morality rate that reflects a kind of risk premium for the insurers instead of taking the risk from the policyholders. Therefore, it is required to use the reference net premium rate II for the calculation of the annuity premium.

On the other hand, the reference net premium rate $\mathrm{I}$ is the mortality rate without reflecting the 


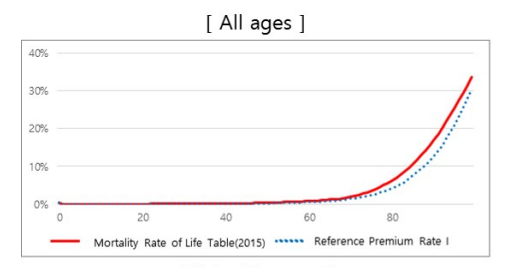

[40 to 60 years ]

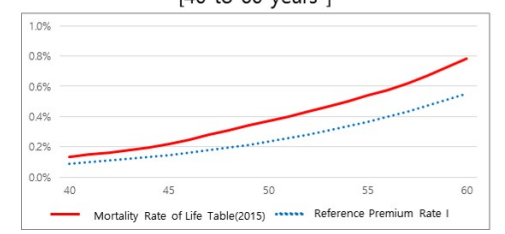

Figure 1: Comparison between mortality rate of life table and reference premium rate $I$.

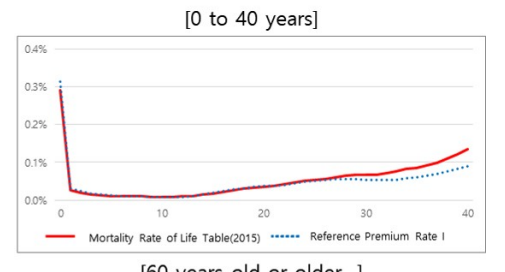

[60 years old or older ]

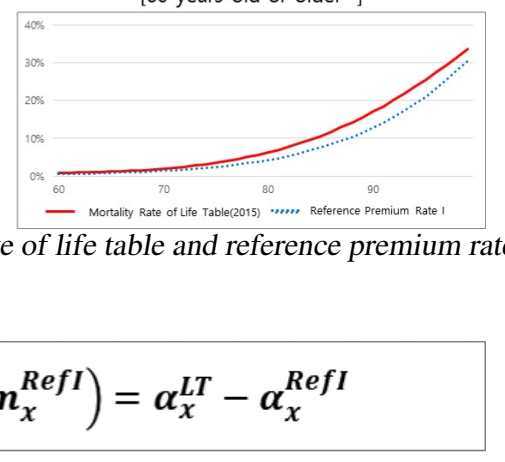

$-$

$$
\ln \left(m_{x}^{L C \prime}\right)=\ln \left(m_{x}^{L C}\right)+\omega_{x}
$$

$$
q_{x}^{L C \prime}=\frac{m_{x}^{L C^{\prime}}}{1+0.5 m_{x}^{L C \prime}}
$$

Figure 2: The process of mortality rate correction.

consideration of risk. Therefore, this rate is used to correct the population difference between the Life Tables and the reference net premium rate. Since the reference net premium rate comes from the mortality model based on annuity holders, the reference rate is different from the result calculated from the mortality model based on the Life Tables for the entire Korean population. This is because the reference rate is from the population of relatively healthy individuals who have had a medical checkup and are notified of health conditions. In general, when comparing the reference net premium rates I and the mortality rates on the Life Tables, the former is lower than the latter.

This study incorporates the modification factor $\left(\omega_{x}\right)$ into the future mortality model through the Lee-Carter model to correct the population difference between the Life Tables and the reference net premium rate. It is assumed that the difference exists by age, and the difference does not change over time. The following figure summarizes these correction steps.

In this study, $m_{x}^{L T}$ is the central death rate on the Life Tables in 2015 while $m_{x}^{\text {RefI }}$ is the central death rate on the reference net premium rate I. Thus, the modification factor $\left(\omega_{x}\right)$ is determined as the difference between the log-transformation of the above two central death rates. The difference between populations can be corrected by additionally incorporating the modification factor into the Lee-Carter model. In Figure 2, LC indicates the results from the Lee-Carter model before correction and LC' is the result from the Lee-Carter model after the correction. 


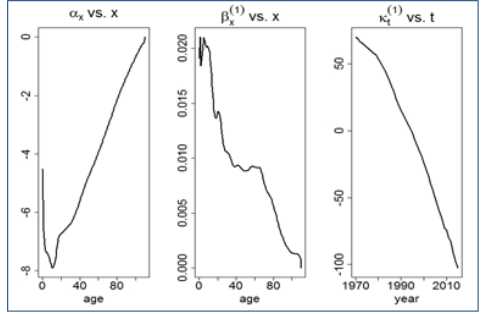

$\ln \left(m_{x}\right)=\alpha_{x}+\beta_{x} k_{t}+\varepsilon_{t}, \varepsilon_{t} \sim N(0,0.007)$

$k_{t}=-3.8334+k_{t-1}+\varepsilon_{t}, \varepsilon_{t} \sim N(0,2.720)$

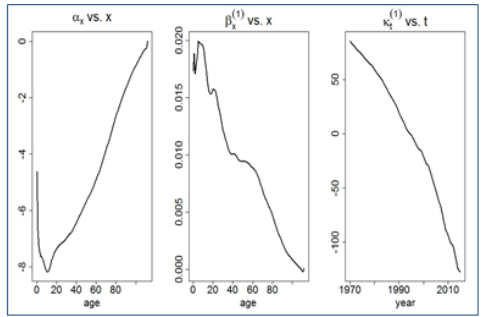

$\ln \left(m_{x}\right)=\alpha_{x}+\beta_{x} k_{t}+\varepsilon_{t}, \varepsilon_{t} \sim N(0,0.036)$

$k_{t}=-4.7379+k_{t-1}+\varepsilon_{t}, \varepsilon_{t} \sim N(0,6.242)$

Figure 3: Estimation results of mortality model (left: male/ right: female).

Lastly, the Life Tables limit 100 years as the upper limit age, while the reference net premium rate limits 110 years for men and 112 years for women as an upper limit age. According to the method of building the Life Tables of Statistics Korea, the estimation for probability of mortality over the age of 85 on the Life Tables is unstable due to the lack of sufficient data for the super-aged. Accordingly, Statistics Korea applied the Coale-Kisker model to extend the upper limit age estimate to 115 years old using the tendency for the mortality rate in the elderly to slow down, and then announced the results for those up to 100 years of age. Since the estimation method using Coale-Kisker model is disclosed, we also calculated the probability of mortality up to 115 years of age. Therefore, it is possible to set the upper limit age of the reference net premium rate as the limit age, 110 years for men and 112 years for women, in this study. In brief, the Coale-Kisker model is described as follows.

$$
m_{x}^{L C^{\prime}}=m_{x-1}^{L C^{\prime}} \exp \left(k_{x}\right), \quad k_{x}=k_{x_{0}}+\left(x-x_{0}\right) s \quad \text { where } \quad x=x_{0}, \quad x_{0}+1, \ldots, x_{\max } .
$$

Note that $x_{0}=85$ and $x_{\max }=115$, and $k_{x}$ is defined as, $k_{x}=\operatorname{In}\left(m_{x}\right)-\operatorname{In}\left(m_{x-1}\right)$ in this study. $\operatorname{In}(3.3)$, $s$ denotes the slope of the change in $k_{x}$ over 85 years old and is represented as follows.

\section{Evaluation of the premium risk in life annuity}

\subsection{Estimation results of mortality model}

In this section, we estimated the coefficients of the Lee-Carter model using male and female mortality data from 46 Life Tables from 1970 to 2015. As a result, we observed that the overall pattern is similar, although there are differences in the coefficients such as age $\left(\alpha_{x}\right)$, period $\left(k_{t}\right)$ and age-specific sensitivity to the period $\left(\beta_{x}\right)$ between males and females. First, the age coefficient represents typical patterns of commonly known age-specific mortality. It starts at a high level at the age of 0 , decreases rapidly in infancy, and increases continuously through adolescence. The period coefficient has a linear trend and shows a decreasing pattern, indicating that the improvement in Korea's mortality rate is continuously and consistently progressing over the entire period. On the other hand, since the coefficient of age sensitivity to the period generally shows a decreasing pattern, it can be seen that the effect of improving the mortality rate gradually decreases as the age increases. The following Figure 3 summarizes the results of estimation for the male and female mortality model.

Next, we incorporate the modification factor which corrects the difference in populations between the Life Tables and reference net premium rate into the Lee-Carter model. Figure 4 shows the future mortality rate of 60 year-old male and female annuity holders in early 2016.

As a result of the mortality model estimation, the life expectancy for the entire Korean population will continue to increase and approach the age of 90 in 2055, and that of the annuity holders will 


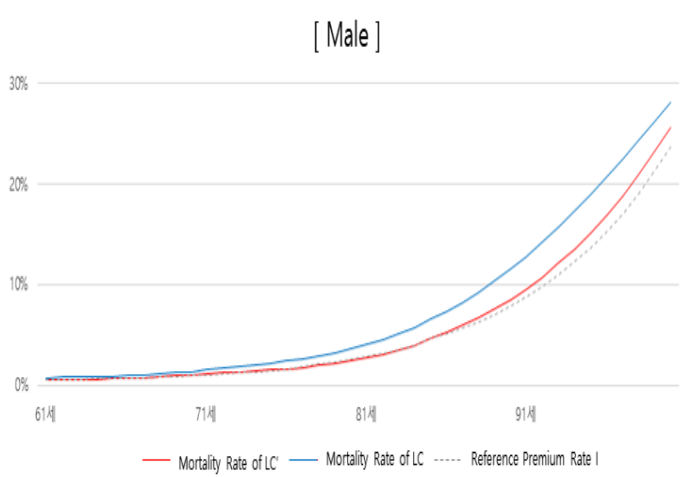

(a) Male

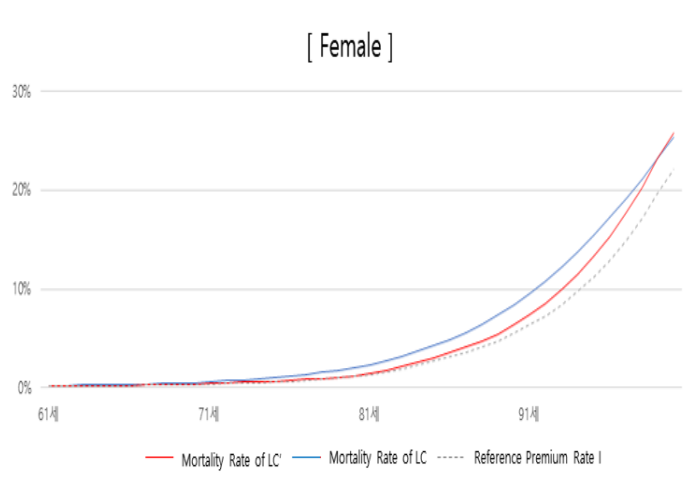

(b) Female

Figure 4: Expectation of future mortality rate for 60-year-old life annuity holders.

Table 3: Trend and forecast of average life expectancy

(Unit : Years)

\begin{tabular}{|c|c|c|c|c|c|c|c|c|}
\hline \multirow{3}{*}{ Gender } & \multirow{3}{*}{ Age } & \multicolumn{5}{|c|}{ Whole nation } & \multirow{2}{*}{\multicolumn{2}{|c|}{$\begin{array}{c}\text { Annuity } \\
\text { Subscriber }\end{array}$}} \\
\hline & & & & & & & & \\
\hline & & 1975 & 1995 & 2015 & 2035 & 2055 & 2035 & 2055 \\
\hline \multirow{2}{*}{ Male } & 0 & 59.81 & 69.2 & 78.46 & 83.45 & 86.98 & $87.48(+4.03)$ & $90.35(+3.37)$ \\
\hline & 60 & 12.54 & 16.22 & 21.71 & 24.99 & 27.79 & $28.47(+3.48)$ & $30.85(+3.06)$ \\
\hline \multirow{2}{*}{ Female } & 0 & 67.72 & 77.44 & 84.67 & 88.37 & 90.76 & $90.39(+2.02)$ & $92.40(+1.64)$ \\
\hline & 60 & 18.31 & 21.15 & 26.45 & 28.80 & 30.93 & $30.73(+1.93)$ & $32.53(+1.60)$ \\
\hline
\end{tabular}

Note: The value in parentheses represents the difference between the life expectancy of annuity holders and the life expectancy of whole population.

Table 4: Assumptions related to life annuity contract for analysis

\begin{tabular}{cc}
\hline \hline Type of product & Whole life annuity \\
Gender & Male or female \\
Age at contract time & 60 -year-old, as of 2016 \\
Number of policyholders & 10,000 policyholders \\
How to pay premium & Lump-sum payment \\
Annuity amount & $1,000,000$ KRW (annual payment) \\
Discount rate & $2.50 \%$ \\
\hline \hline
\end{tabular}

exceed the age of 90. This increase in life expectancy implies an increase in the payment period for the annuity holders, so the insurers may be concerned about whether an appropriate premium reflecting the increase in life expectancy is charged or not. That is, there are concerns about whether the level of premium risk currently borne by insurers is appropriate.

\subsection{Assumptions for life annuity}

The assumptions for life annuity to evaluate the level of premium risk for insurers are as follows: For the convenience of the analysis, it is assumed the simple basic whole life annuity due and payment is 1 million won to living policyholders at the beginning of the period. Insurance premium is assumed to be a single premium. To focus on the evaluation of premium risk, the discount rate is fixed at $2.5 \%$. The single premiums for men and women are 20.45 million and 22.62 million won, respectively. As noted above, the applied rate is the reference net premium rate II on the 8th experience life table. 
Create survival probability scenarios for the whole nation $\left(p_{60+t}^{L C}\right)$

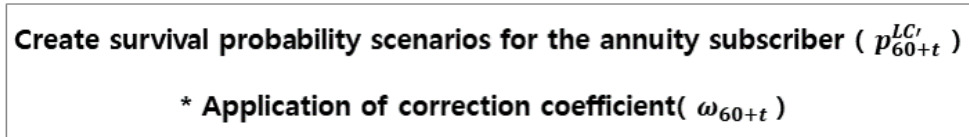

* Application of correction coefficient $\left(\omega_{60+t}\right)$

Create survivor scenarios for the annuity subscribers $\left(L_{60+t}^{L C \prime}\right)$

${ }^{*} L_{60+t}^{L C C^{\prime}} \sim$ Binomial $\left(L_{60+t-1}^{L C^{\prime}}, p_{60+t}^{L C^{\prime}}\right), L_{60}^{L C \prime}=10,000$

Figure 5: The process of scenario generation for annuity holders.
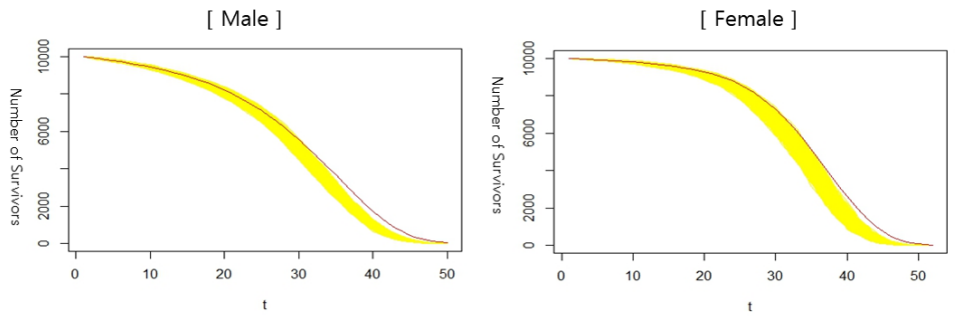

Figure 6: Generation results of scenarios for annuity subscribers.

\subsection{Results of the scenario generation for future survivors}

Based on the mortality model in subsection 4.1 and the assumptions in 4.2, 10,000 scenarios by future year for 10,000 annuity holders aged 60 years are generated. The summarization of the process to generate the scenarios is shown in Figure 5.

We can reflect the variability of the mortality model itself (Step 1), correction of the mortality rate due to the population differences and the independence of each annuity holder's survival through the above process. The result of generating 10,000 scenarios for the number of male and female survivors is shown on Figure 6. The curve in Figure 6 is the number of survivors in the future when the reference net premium rate II is applied. Since most of the future survivor scenarios are located below this curve, the number of the survivors in the scenario is mostly less than the number of survivors assumed in the premium calculation. That is, it can be seen that the premium rate applied by the insurers is at a fairly conservative level, fully reflecting the expected improvement of mortality in the future.

\subsection{Evaluation of the premium risk for life annuity}

In the previous subsection, it is confirmed that the premium rate applied by insurers is sufficiently conservative as a result of the scenario generation for the future survivors. We derive the probability distribution of the insurer's profit to investigate more accurately in Figure 7. Figure 7 depicts the probability distribution of the present value for the insurer's profit. We also check the insurer's profit under the worst-case scenario. Note that we define the worst-case scenario as follows: At first, 10,000 scenarios are listed in insurer's profit order, from low to high. The $100^{\text {th }}$ scenario $\left(500^{\text {th }}, 1,000^{\text {th }}\right)$, 

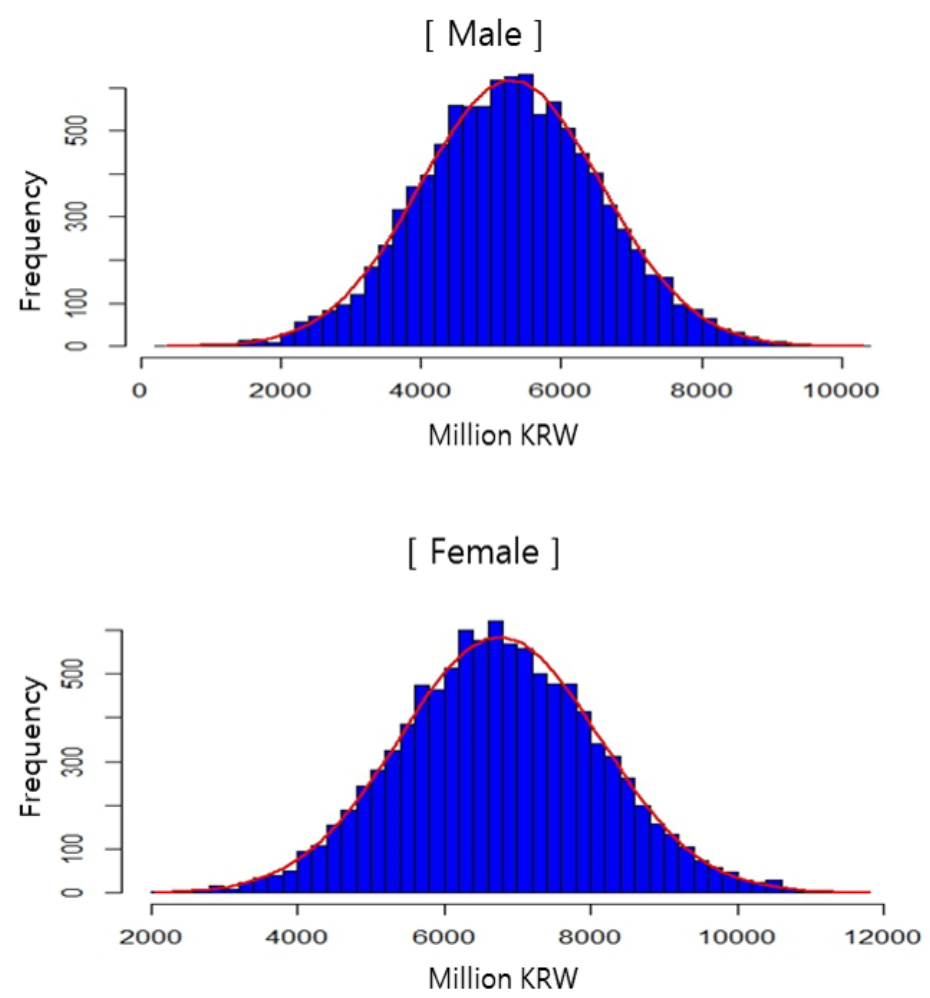

Figure 7: Probability distribution of present value for insurer's profit.

Table 5: Assumptions related to life annuity contract for analysis

\begin{tabular}{ccccccc}
\hline \hline \multirow{2}{*}{ Premium income } & \multicolumn{5}{c}{ Present value of insurance company's profit } \\
\cline { 3 - 6 } & \multirow{2}{*}{ Male } & Mean & Standard deviation & 1 Percentile & 5 Percentile & 10 Percentile \\
& \multirow{2}{*}{204,545} & 6,180 & 1,456 & 2,788 & 3,823 & 4,342 \\
& \multirow{2}{*}{ Female } & $(3.02 \%)$ & $(0.71 \%)$ & $(1.36 \%)$ & $(1.87 \%)$ & $(2.12 \%)$ \\
& \multirow{2}{*}{226,246} & 7,947 & 1,566 & 4,384 & 5,410 & 5,951 \\
& & $(3.51 \%)$ & $(0.69 \%)$ & $(1.94 \%)$ & $(2.39 \%)$ & $(2.63 \%)$ \\
\hline \hline
\end{tabular}

Note: The value in parentheses is the proportion of insurer's profit to premium income.

that is at 1 percentile( 5 percentile, 10 percentile), is considered as the worst-case scenario. This implies that for the scenario at 1 percentile, the probability of a lower profit being realized than the profit generated under this scenario is less than $1 \%$. Table 5 summarizes the characteristics of the profit distribution such as mean and standard deviation. We can observe that the premium risk of the insurers due to the sales of life annuity is not a large concern. That is, even if the above worst-case scenario is applied, there is no loss of insurers in both men and women.

These results show that the premium risk of insurers due to the sales of life annuities is limited. Rather, considering only the premium risk, it leads to the conclusion that the insurers should be more active in selling life annuities. However, this study has the following limitations and needs to fully consider the limitations: First, there exists an interest rate risk as another important risk factor; in 


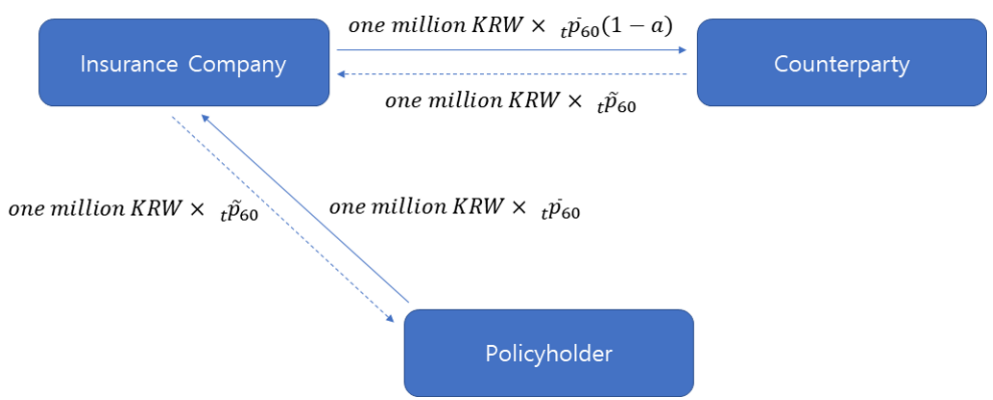

Figure 8: Structure and cash flows of longevity swap.

this study, the interest rate is fixed and thus, the relationship between the premium risk and interest risk is not considered. Second, the Lee-Carter model is applied for future mortality, but if a more sophisticated model is applied, the results may be different. According to Kim (2012a), when the Lee-Carter model is applied to estimate the mortality rate in Korea, there exist systematic factors that cannot be explained in the Lee-Carter model. He also estimates that the factors may come from the cohort effect. Nevertheless, in light of the results of this analysis, it is highly likely that the level of premium risk for insurers due to the sales of life annuities will be less than generally expected.

\section{Longevity swap in Korea insurance market}

\subsection{The structure of trading in longevity swap}

The previous analysis on premium risk shows that the current level of premium risk for insurers in Korea is noted as a level of concern. This implies that the premium rate applied to life annuity is sufficiently conservative compared to future mortality estimates based on the Lee-Carter model, which means that the insurers are less likely to report loss from the sales of annuities.

However, as the result of this analysis, even if the premium risk that the insurers have is limited, changes in the insurance regulatory environment, such as the introduction of IFRS17 and the strengthening of the solvency system, which are planned in the future, are further reasons that lower the aggressiveness of insurers to sell life annuities. The introduction of IFRS17 and the reinforcement of the solvency system require Korean insurers to expand large-scale capital and establish an advanced risk management system. Products with long term maturity such as life annuity tend to add the difficulties of capital expansion and risk management, so insurers generally do not prefer these products.

As a way to activate the life annuity market, it is possible to consider the application of longevity swaps that have already been commercialized in advanced countries. A longevity swap can be customized according to various circumstances based on an agreement between the parties to the transaction, and has an advantage of low counter-party risk by exchanging only the difference in the previously agreed cash flow without exchanging principal between the parties. Dowd et al. (2006) argued that a longevity swap is easy to develop and flexible in the product structure, making it suitable for insurers to hedge the premium risk.

The structure of the longevity swap in this subsection is a form of Plain Vanilla Swap in which insurers and counter-parties periodically exchange fixed cash flows and floating cash flows based on the mortality rate performance. The following Figure 8 summarizes the proposed longevity swap structure and cash flows to assess the possibility of introducing longevity swaps in the life annuity 
Table 6: PV of insurer's and counter-party's profit from longevity swap transaction (male)

\begin{tabular}{crrrrr} 
& & & & (Unit : million KRW) \\
\hline \hline \multirow{2}{*}{$\mathrm{a}$} & \multirow{2}{*}{ Insurer } & \multicolumn{3}{c}{ Counter-party } \\
\cline { 3 - 6 } & & Mean & 1 percentile & 5 percentile & 10 percentile \\
\hline $00 \%$ & 2,045 & 6,180 & 2,788 & 3,823 & 4,342 \\
$1.00 \%$ & 4,091 & 4,134 & 743 & 1,778 & 2,296 \\
$2.00 \%$ & 6,136 & 2,089 & $-1,303$ & -267 & 251 \\
$3.00 \%$ & 43 & $-3,348$ & $-2,313$ & $-1,795$ \\
\hline \hline
\end{tabular}

Table 7: PV of insurer's and counter-party's profit from longevity swap transaction (female)

\begin{tabular}{ccrrrr} 
& & & & (Unit : million KRW) \\
\hline \hline \multirow{2}{*}{$\mathrm{a}$} & \multirow{2}{*}{ Insurer } & Mean & 1 percentile & 5 percentile & 10 percentile \\
\cline { 3 - 6 } & & 7,947 & 4,384 & 5,410 & 5,951 \\
$0.00 \%$ & 0 & 5,684 & 2,122 & 3,147 & 3,688 \\
$1.00 \%$ & 2,045 & 3,422 & -141 & 885 & 1,426 \\
$2.00 \%$ & 4,091 & 1,159 & $-2,403$ & $-1,378$ & -837 \\
$3.00 \%$ & 6,136 & &
\end{tabular}

market of Korea. For the consistency of the analysis, the assumptions applied in the previous sections are maintained. In addition, ${ }_{t} \bar{P}_{60}$ is the future survival rate (fixed cash flows) based on the premium rate (reference net premium rate II) to calculate annuity premium and ${ }_{t} \bar{P}_{60}$ is the real survival rate (floating cash flows).

In the longevity swap structure presented in Figure 8, $a$ refers to the ratio of fixed income to fixed cash guaranteed by insurers from the swap. That is, $a$ implies the profit rate of the insurers instead of providing the cash flows with a high probability of generating profits to counter-parties due to changes in the insurance regulatory environment, such as the introduction of IFRS17 and the strengthening of the solvency system, in spite of the limited premium risk of the insurers. The larger $a$ is, the more the insurers can fully transfer the premium risk arising from the life annuity to the counter-parties of the longevity swap and ensure the insurers have more fixed income. However, the expected return of the counter-party is lowered. Therefore, the insurers and the counter-parties can make the proposed longevity swap contract by negotiating the appropriate level of $a$.

\subsection{The possibility of longevity swap transaction}

By applying the previous Lee-Carter model-based future mortality scenario to the proposed Plain Vanilla Swap-type longevity swap structure, it is possible to evaluate the applicability of the longevity swap transaction to Korean life annuity market. That is, under the proposed longevity swap structure, the applicability of the longevity swap transaction can be assessed by deriving fixed profits of the insurers and a selection area of a at which the insurers can achieve the targeted risk adjustment performance.

The following Tables 6 and 7 summarize the expected present value (PV) of fixed profits for the insurers and the profits for the counter-parties when a is $0 \%, 1 \%, 2 \%$ and $3 \%$ by dividing counterparties into male and female, respectively.

According to Tables 6 and 7, through a longevity swap contract, insurers can have more profits by completely eliminating the premium risk caused by the sales of life annuities and at the same time increase a according to the result of negotiations. Therefore, if a longevity swap becomes possible, it is possible to actively respond to the increase in demand for life annuities without the cost of capital expansion caused by the sales of life annuities, even when IFRS17 is introduced and the solvency 
Table 8: Investment decision criteria for longevity swap (example)

\begin{tabular}{cc}
\hline \hline Required capital & 1 percentile of expected loss $\times 200 \%$ \\
Investment decision criteria & Expected profit / Required capital $\geq 8 \%$ \\
\hline \hline
\end{tabular}

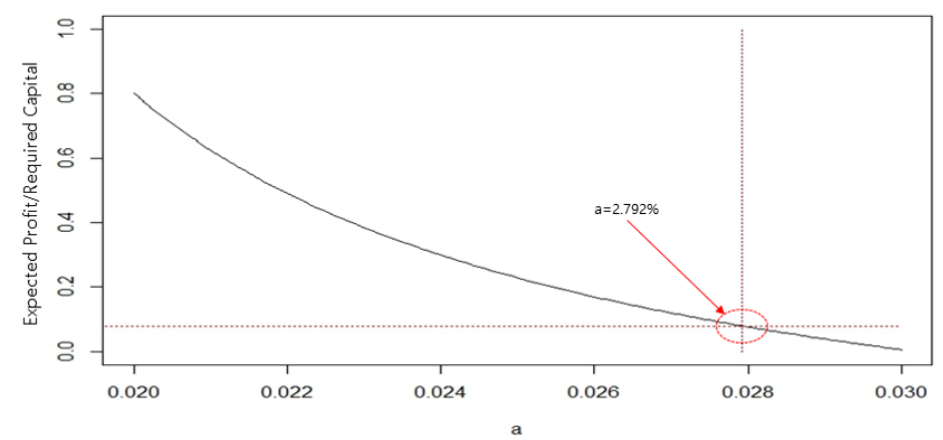

Figure 9: Ratio of expected profit to required capital in longevity swap investment (male).

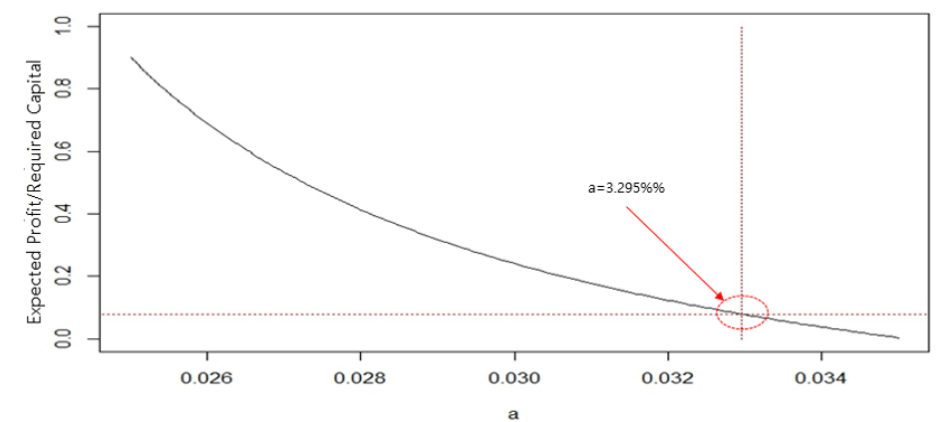

Figure 10: Ratio of expected profit to required capital in longevity swap investment (female).

system is strengthened. However, in exchange for transferring the premium risk to the counter-party, the longevity swap transaction can actually be made if a negotiation proposal can be presented within the domain of the counter-party's risk appetite and level of risk management.

The following Table 8 is an example of the criteria for determining whether to invest in longevity swap, taking into account the risk appetite and level of risk management of the counter-party. That is, it is assumed that the counterparty can take the risk up to twice the expected loss (required capital) of 1 percentile, and that the investment is determined when the risk-adjusted performance, which implies the expected return relative to the required capital, exceeds $8 \%$

As a result of applying the criteria for determining the investment of counter-party in longevity swap, the selection area for a of the longevity swap for male annuity holders is $(0 \%, 2.792 \%)$, and that for $a$ of the longevity swap for female annuity holders is $(0 \%, 3.295 \%)$. The insurers and counterparties can make a longevity swap contract that satisfies each other by determining $a$ within the selection area of a noted above. For example, in a longevity swap for male annuity holders, if $a$ 
is determined to be $2.792 \%$, the insurers completely eliminate the premium risk inherent in the life annuity. The insurers can have a stable profit $2.792 \%$ of the single premium for annuity without capital expansion as well. In addition, the counter-party needs 5,841 million won as required capital to prepare for premium risk of life annuity, but the expected return from this is 471 million won, which is an $8 \%$ ratio of expected return to the required capital. The counter-party can invest the alternative asset that meets the target level of risk management of the investment.

\section{Conclusion}

Korea, which is experiencing an unprecedented rapidly aging population, is facing a serious problem of poor retirement preparation on a nationwide scale. To solve this problem, it is essential to expand the role of annuity as the most basic means of guaranteeing retirement income. However, the guarantees of retirement income through public annuity are not sufficient due to concerns over the depletion of pension funds and low birth rate. In the end, it is necessary to respond to the demand for annuity by activating personal annuity. However, the activation of personal life annuity market is not easy due to the lack of expertise of insurers and changes in the insurance regulatory environment.

This study focuses on premium risk, one of the causes of insurers' passive attitude for selling annuities. As a result of analysis using the Lee-Carter model, which is a representative future mortality estimation model, we find that the level of premium risk of insurers in Korea is not as large as commonly known by simulation based on 10,000 scenarios for 10,000 annuity holders. That is, despite the expected rapid aging, insurers are already fully reflecting the expected future mortality improvements in insurance premium. In particular, even if the worst-case scenario is applied, it is confirmed that insurers in Korea do not suffer losses for all genders. These results suggest that insurers should move away from their current passive annuity sales practices and engage in more aggressive sales strategies. However, changes in the regulatory environment, such as the introduction of IFRS17 and the strengthening of the solvency system, are reasons for insurers to hesitate in selling life annuities. Therefore, even if the longevity risk is low, it is difficult to lead to an immediate increase in life annuity sales.

This study proposes a longevity swap to solve the aging and elderly poverty problem while alleviating concerns about premium risk for insurers. We identify in an example that both insurers and counter-parties in the longevity swap could meet each other's needs with a Plain Vanilla Swap, a basic way of periodically exchanging fixed and floating cash flows based on the performance of the mortality rate. This longevity swap may be attractive enough for investors when the counter-parties can obtain a new investment alternative that can expect excess returns instead of taking the premium risk. We show through several examples that longevity swap can be marketable transaction. The counter-parties can also have an opportunity to diversify their portfolio since the longevity risk has zero correlation with the risks in an existing portfolio and capital market. In addition, insurers can sell life annuity more actively as they may not be burdened with raising capital due to the sale of life annuity even when IFRS17 is introduced and Solvency system is strengthened through longevity swap.

However, a longevity swap alone cannot fully guarantee the activation of personal life annuity. This is because interest rate risk must be considered together with premium risk in order to vitalize the transaction of life annuity. As an option, although regulatory authorities have not yet allowed it, it is possible to review using structured reinsurance. In addition, a study on the development of a new type of life annuity product structure that can naturally hedge interest rate risk and premium risk as a measure that does not require regulatory considerations can be examined in a further study. Lastly, as we noted above, the reference net premium rates for the $8^{\text {th }}$ experience mortality table are used in 
this study. These data are not disclosed and the reference net premium rates for the 9th experience mortality table are not available. Thus, due to the limitations in data availability, the Life Tables from 1970 to 2015 corresponding to the reference net premium rates for the $8^{\text {th }}$ experience mortality table are used to estimate the mortality model. In future research, we hope the model can be improved based on recent data updates.

\section{References}

Blake D and Burrows W (2001). "Survivor bonds: Helping to hedge mortality risk", The Journal of Risk and Insurance, 68, 339-348.

Blake D, Cairns AJG, Dowd K, and Kessler AR (2019). "Still living with mortality: The longevity risk transfer market after one decade", British Actuarial Journal, 24.

Biffis E, Blake D, and Pitotti L, and Sun A (2016). "The cost of counterparty risk and collateralization in longevity swaps", Journal of Risk and Insurance, 83, 387-419.

Booth H, Maindonald J, and Smith L (2002). "Applying Lee-Carter under conditions of variable mortality decline", Population Studies, 56, 325-336.

Booth H and Tickle L (2003). "The future aged: new projections of Australia's elderly population", Australasian Journal on Aging, 22, 196-202.

Callot L, Niels H, and Malene K-L (2016). "Deterministic and stochastic trends in the Lee-Carter mortality model", Applied Economics Letters, 23, 486-493.

Cairns AJG, Blake D, and Dowd K (2006a). "A two-factor model for stochastic mortality with parameter uncertainty: theory and calibration", Journal of Risk and Insurance, 73, 687-718.

Cairns AJG, Blake D, and Dowd K (2006b). "Pricing death: Frameworks for the valuation and securitization of mortality risk", ASTIN Bulletin: The Journal of the IAA, 36, 79-120.

Cairns AJG and Boukfaoui GE(2019). "Basis risk in index-based longevity hedges: A guide for longevity hedgers", North American Actuarial Journal, 1-22.

Coughlan G, Epstein D, Sinha A, and Honig P (2007). “q-forwards: Derivatives for transferring longevity and mortality risks", JPMorgan Pension Advisory Group, London.

Cowley A and Cummins J (2005). "Securitization of life insurance assets and liabilities", The Journal of Risk and Insurance, 72, 193-226.

Dowd K, Blake D, Cairns AJG, and Dawson P (2006). "Survivor swaps", The Journal of Risk and Insurance, 73, 1-17.

Financial supervisory service of Korea (2019). "The analysis of annuity-saving in 2018".

Haberman S and Renshaw A (2012). "Parametric mortality improvement rate modelling and projecting", Insurance: Mathematics and Economics, 50, 309-333.

Haberman S and Renshaw A (2013). "Modelling and projecting mortality improvement rates using a cohort perspective", Insurance: Mathematics and Economics, 53, 150-168.

He W, Goodkind D, and Kowal P (2015). "An Aging World: 2015”, United States Census Bureau.

Hunt A and Blake D (2021). "On the structure and classification of mortality models", North American Actuarial Journal, 25, 215-234.

Lundström H and Qvist J (2004). "Mortality forecasting and trend shifts: An application of the Lee-Carter model to Swedish mortality data", International Statistical Review, 72, 37-50.

Kim SJ (2012a). "A Study on the prediction of mortality rate using Lee-Carter model", The Journal of Actuarial Science, 4, 47-66.

Kim SJ (2012b). "A comparison study on stochastic mortality models for measuring longevity risk", Korea Journal of Insurance, 93, 213-235. 
Kwon SH and Jang JM (2011). "How to launch longevity bonds in the aging era”, Korea Capital Market Institute.

Lee RD and Carter LR (1992). "Modeling and forecasting US mortality", Journal of the American Statistical Association, 87, 659-671.

Michaelson A and Mulholland J (2014). "Strategy for increasing the global capacity for longevity risk transfer: Developing transactions that attract capital markets investors", The Journal of Alternative Investments 17, 18-27.

Mitchell D, Brockett P, Mendoza-Arriaga R, and Muthuraman K (2013). "Modeling and forecasting mortality rates", Insurance: Mathematics and economics, 52, 275-285.

OECD (2017). "Pension at glance".

Plat R (2009). "On stochastic mortality modeling", Insurance: Mathematics and Economics, 45, 393-404.

Renshaw AE and Haberman S (2003). "Lee-Carter mortality forecasting with age-specific enhancement", Insurance: Mathematics and Economics, 33, 255-272.

Sung JH and Shin HY (2007). "Diagnosis of the current securitization markets hedging mortalityrelated risks and some notes on their crucial issues", Korea Journal of Insurance, 77, 291-323.

Tuljapurkar S, Li N, and Boe C (2000). "A universal pattern of mortality decline in the G7 countries", Nature, 405, 789-792.

UN (2015). "World population prospects".

UNFPA (2020). "State of World Population 2020".

Wilmoth JR (1996). "Mortality projections for Japan: A comparison of four methods", Health and Mortality Among Elderly Populations, 266-287. 
